\title{
Paradigm shift to enhanced water supply planning through augmented grids, scarcity pricing and adaptive factory water: A system dynamics approach
}

\author{
O. Sahin ${ }^{a}$, R.S. Siems ${ }^{a}$, R.A. Stewart ${ }^{a}$ and Michael G. Porter ${ }^{b}$ \\ ${ }^{a}$ Centre for Infrastructure Engineering and Management, Griffith University, Queensland, Australia \\ ${ }^{b}$ Alfred Deakin Research Institute Deakin University, Melbourne Victoria, Australia \\ Email: o.sahin@griffith.edu.au
}

Corresponding author:

Dr Oz Sahin

Griffith School of Engineering, Gold Coast Campus, Griffith University, Parklands Drive, Southport, QLD

4222, Australia;

Phone: +61755528778

Email: $\underline{\text { o.sahin@griffith.edu.au }}$

\section{Highlights}

- System dynamics model integrates supply, demand and financial dimensions.

- Diverse supply source portfolios that are grid connected alleviates water scarcity.

- Desalination reduces need for restrictions compared to a rain-dependent portfolio.

- Pressure retarded osmosis technology integration into desalination component of water supply networks for renewable energy.

- Scarcity pricing is an effective strategy for reducing demand while simultaneously generating the additional revenues.

\begin{abstract}
:
This paper details a system dynamics model developed to simulate proposed changes to water governance through the integration of supply, demand and asset management processes. To effectively accomplish this, interconnected feedback loops in tariff structures, demand levels and financing capacity are included in the model design, representing the first comprehensive life-cycle modelling of potable water systems. A number of scenarios were applied to Australia's populated South-east Queensland region, demonstrating that introducing temporary drought pricing (i.e. progressive water prices set inverse with availability), in conjunction with supply augmentation through rain-independent sources, is capable of efficiently providing water security in the future. Modelling demonstrated that this alternative tariff structure reduced demand in
\end{abstract}


scarcity periods thereby preserving supply, whilst revenues are maintained to build new water supply infrastructure. In addition to exploring alternative tariffs, the potential benefits of using adaptive pressureretarded osmosis desalination plants for both potable water and power generation was explored. This operation of these plants for power production, when they would otherwise be idle, shows promise in reducing their net energy and carbon footprints. Stakeholders in industry, government and academia were engaged in model development and validation. The constructed model displays how water resource systems can be reorganised to cope with systemic change and uncertainty.

Keywords: Water security; forecasting; desalination; scarcity pricing; temporary drought pricing; system dynamics modelling. 


\section{SOCIO-ENVIRONMENTAL SYSTEM CONTEXT}

Potable water security is a growing concern, as population growth, development and climatic change increasingly limit the potential of traditional rain-dependent sources for augmenting supply. This poses new challenges to the governance of potable water resource systems.

Whilst Australia may appear abundant in its water supply, only utilising approximately 5\% of its total renewable freshwater resources (SoE, 2013), it faces gross geospatial supply-demand mismatches and is afflicted with the highest rainfall variability of any continental region. As a consequence of this, Australia possesses more water storage per capita than any other nation, and is heavily reliant on surface water, which represents 95\% of distributed supply (ABS, 2012). This reliance has already led to significant social and economic consequences as a result of severe restrictions in the SEQ region, as experienced during the recent 'Millennium Drought' from 2001-2009 (Pink, 2012; QWC, 2012b). Water shortages were severe, with inflows reduced by over 70\% in some years (Pittock and Connell, 2010). This shaved more than $1 \%$ off the nation's economy in 2002/03 (Australian Government et al., 2013), and similarly in 2006/07 (WEFWI, 2011), and led to water restrictions in many major metropolitan areas. The lack of adequate mitigation measures was viewed publicly as a major failure of water management (Killoran, 2013a), leading to a rush of new supply augmentation solutions being implemented, many of which have been of limited effectiveness (Stewart, 2011; Siems et al., 2013).

Thus, with future drought inevitable, endogenously driven water governance change is already required. This need is compounded by a consensus of expectation that exogenously driven population growth and climate change will occur (Heggen, 2000; Pink, 2012), which will exacerbate supply-demand mismatches. It has been forecast that all Australian capital cities will face decreased average annual rainfall and increased average annual temperatures for most climate change scenarios (Pearce et al., 2007; ABS, 2012). Southern and eastern Australia, where the majority of the population resides, will experience a decrease in reliability of water supply(CSIRO, 2012). The result of this will be a decline in supply available for irrigation, domestic use and industry, combined with heightened demand. Hennessy et al. (2007) considers water security as one of the six key risks to Australia under a changing climate, with stream flow expected to decline between 16 and $48 \%$. While future water supply will likely be more variable, the national population could nearly double in the next 50 years, with the majority of this growth expected in the existing urban areas (Sivertsen et al., 2012).

Rain-independent supply options, such as desalination plants, can potentially alleviate water scarcity, ensuring a more reliable supply. In order to be effective, these systems require long term planning and guaranteed revenue streams; necessities which are typically absent in times of water shortage. Currently, water shortages result in progressively severe water restrictions and end-use prohibition (i.e. no lawn irrigation), which reduce socio-economic wellbeing (Grafton and Ward, 2008) and significantly cuts government revenue streams (Jenkins et al., 2003). An availability based cost structure, as opposed to 
restrictions, can generate the finances necessary to diversify the current water supply mix, reducing reliance on surface water. Few studies have investigated using progressive volumetric pricing linked to a regions' water availability instead of restrictions, despite the negative social consequences of the latter (Grafton and Ward, 2008).

The use of rain-independent supply sources, coupled with scarcity pricing, alters existing relationships within potable water resource systems. Desalination plants create new relationships, including feedback (carbon emissions) to the driving exogenous forces upon which the endogenously driven change (water governance reform) originates, which must also be assessed and minimised.

This paper details a System Dynamics Model (SDM) developed to explore methods to minimise Southeast Queensland's (SEQ) exposure to water shortages over the next 100 years, through fundamental water governance reform, leading to system wide changes. These changes to the system take 3 forms: (a) increasing supply capacity with rain-independent supply; (b) changes to demand management practices; and (c) asset management optimisation. The model includes representation of anticipated externally driven changes to the underlying system as time progresses. Potential methods to minimise the negative impacts of reform on the socio-environmental system are also incorporated.

\section{APPROACH TO REPRESENTING SYSTEMIC CHANGE}

Previous water resource system models have typically been supply-side oriented. This research sought to integrate demand, supply and asset management processes, to create a more holistic representation of the coupled socio-environmental system, as illustrated in Figure 1 and discussed below. For the purposes of this paper, asset management encapsulates both the financial interactions influencing the management of water infrastructure, and the operating procedures that determine the utilisation of this infrastructure. Rather than solely relying on academic input for system model conceptualisation and development, a range of stakeholders including consultants, government officers and community representatives were involved in the process. They were also consulted to determine the best way to display the various outputs of the model to both water industry professionals and laypersons.

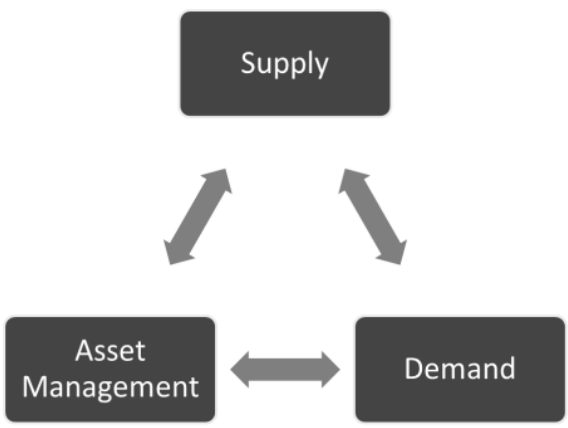

Figure 1. Proposed approach to representing SEQ water resource system processes and consequences. 


\subsection{Review of relevant modelling techniques}

Water supply-demand systems, like most environmental systems, are complex and highly dynamic with many feedbacks and a large number interdependent elements. To address such environmental problems effectively, it is important and necessary that the dynamic character and complexity of these systems are taken into account. The ultimate goal of such analyses is to provide information to improve the decision making process, particularly an improvement in our ability to understand and evaluate environmental problems. Simulation, as defined by Borshchev and Filippov (2004), is the process of model execution that takes the model through (discrete or continuous) state changes, over time. Therefore, simulation modelling is a better answer for complex problems to be analysed realistically and in detail, through its mathematical simplicity and versatility.

Kelly et al. (2013) completed a recent comprehensive review of five popular approaches (i.e. systems dynamics, Bayesian networks, coupled component models, agent-based models and knowledge-based models) for modelling integrated systems and produced extensive guidance on the most appropriate methods to select for particular system modelling problems. Following their guidance, a further review of the two most suitable approaches for dynamic modelling, namely, System Dynamics (SD) and Agent-Based Modelling (ABM), was conducted. These are categorised into distinct concepts of seeing and modelling time: discrete time and continuous time. Underlying these approaches are control theory and the complexity theory (Scholl, 2001b, a). The discrete concept of time is based upon the distinction between time-points and finite time intervals. In contrast, the continuous concept deals with changes over time, based on infinitesimal mathematics. Mathematically, continuous changes in a SD model are modelled by differential equations or mathematical integration over time. According to Frenkiel and Goodall (1978), who identified the relationships between major simulation techniques, a discrete simulation is often appropriate for situations where the system being studied contains a number of separate items, and each item has its own characteristics and period of existence within the system. In a discrete technique, changes in the state of the system are conceptualised as taking place in discrete jumps, corresponding to the arrivals, departures, or other critical changes in the status of the individual items. In contrast, changes occur continuously and smoothly in the continuous simulation technique.

Ossimitz and Mrotzek (2008) argue that although SD is generally considered to be a methodology based on continuous time; it is compatible both with the continuous and the discrete concept of time. This conclusion is similar to that of Huggett (1993), who found that, although continuous aggregated models of environmental systems have their uses, more complex discrete disaggregated models are usually preferred. Nevertheless, in aggregated models, any of the four permutations of continuous and discrete time and statespace formats may be used. For this reason, SD can be considered as a hybrid methodology. Hence, this "hybrid" potential makes System Dynamics a superior technique for modelling time, as it combines the advantages of continuous and discrete time concepts. Hassanzadeh et al. (2014) provide a recent example of using SD for integrated water resources management for the Saskatchewan portion of the trans-boundary 
Saskatchewan River Basin in western Canada. They successfully integrated into the SD model economic dimensions related to farmland irrigation decisions with the typical catchment water balance modelling.

Based on the above arguments, SD was considered to be the most appropriate approach for modelling the urban water supply-demand system as this system contains both discrete and continuous elements.

\subsection{Understanding and treatment of uncertainties}

There exist a range of uncertainties often resulting from incomplete scientific understanding of the various processes. Although uncertainties are an important aspect in the model building and scenario analysis process, a formal and comprehensive treatment of uncertainty is often difficult to achieve in practice.

According to Robinson (2003), three main sources of uncertainty are: (1) the lack of knowledge about system conditions and underlying dynamics; (2) the prospects for innovation and surprise; and (3) the intentional nature of human decision-making. The adequate treatment of these uncertainties is a crucial aspect in the development and application of any model. (Mannermaa, 1991) suggests that some sources of uncertainty can be reduced by progressively improving the models and including more variables. Scenarios are also widely used to improve our understanding of the complex interactions of the environmental systems and human activities. For example, in the climate change context, scenarios provide plausible descriptions of how the future might unfold under changing climatic conditions (Moss et al., 2010). Additionally, for the model building process, the sound communication of uncertainties and stakeholders' participation is crucial. Further, participation and consensus building around scenarios can help to deal with uncertainty.

Accordingly, a variety of measures in designing the model has been adopted, such as stakeholder and expert consultations and workshops for scenario analysis and the model building process, the use of scenarios to explore outcomes, and sensitivity analyses to systematically minimize the potential influence of uncertainties in the model output. For example, rather than relying on a single point prediction in relation to future population growth, climate and rainfall variability, a range of scenarios were chosen, within which the model was proven to work, with sufficient accuracy. In addition, sensitivity analyses were performed to explore the sensitivity of the model results to changes in any important model input. The results helped us to identify any systematic bias in the model's calculations, and provided information about whether the model needs to be revised, in light of this new information.

\subsection{Changing supply and demand for potable water in the study region}

SEQ contains approximately $65 \%$ of the State of Queensland's population, in just a fifth of the state's total land area. The region has experienced population growth above the national average over the past decade, which is expected to continue into the $21^{\text {st }}$ century (Sivertsen et al., 2012). Urban water demand comprises $65 \%$ of the region's total water usage (QWC, 2010, 2012b), with $96 \%$ of this sourced from surface 
water supplied reservoirs. This generates a large reliance on precipitation, such that a large storage capacity (i.e. 2,200 GL) is required to cope with low inflow years (Marsden and Pickering, 2006; BOM, 2013). Dam yields have been found to be very sensitive to global changes in climate and typical variability in conditions (NWC, 2006; NCEDA, 2010). Currently the storage capacity equates to six years full supply based on current demand.

SEQ experienced particular hardship in the Millennium Drought. At one point the region's 12 dam supply network fell to under $14 \%$ capacity, seeing water restrictions at their most severe (Frontier Economics, 2011). For much of the drought dam levels were below $40 \%$. To raise water security a number of initiatives were introduced, such as mandated internally plumbed rainwater tank systems on new residential households, and the construction of a desalination plant (Stewart, 2011). The drought has currently abated, however, there is widespread public and political uncertainty on how to best prepare the water supply system for future stresses (Killoran, 2013a).

\subsection{Coping with systemic change: temporary drought pricing}

Historically water governance has been based on the premise that drinkable water is sourced from a finite resource supply, with only so much surface water available at any given time. This premise is no longer valid, due to the development of desalination and water recycling technologies that allow coastal communities to produce potable water at a cost. Ongoing urban water restrictions are inequitable and an inefficient means of balancing supply and demand, according to the National Water Commission (Frontier Economics, 2008). Applying restrictions also reduces revenue streams to water businesses at the same time that they are seeking to implement costly new water supply and system efficiency investments (Jenkins et al., 2013). Often, the perverse outcome of this traditional control oriented governance model is a water price path well above inflation long after the drought has abated and dam supplies are plentiful.

The Australian water supply market is not laissez-faire in any sense, attracting strict regulation and typically operating under government controlled monopolies. However, the forces of supply and demand can still be allowed to interact to some extent within this government regulated framework. Progressive scarcity based pricing mechanisms, or Temporary Drought Pricing (TDP), allow water tariffs to be set inversely to potable water availability. In the case where a resource is available such that anyone who desires it can consume it without affecting the ability of others to do the same, it is not considered scarce in an economic sense, and should attract a lower value (NWC, 2006; Frontier Economics, 2008; Grafton and Ward, 2010). This concept is presently been trialled in Denver (CO, United States), with water being charged progressively based on usage (i.e. block tariff), with a progressive drought tariff also added when applicable per 1,000 gallons (DW, 2013). Coupling inclining block and scarcity pricing regimes is a highly appropriate way to properly price water but also maintain the essential equity objectives of water provision. 
TDP accomplishes two crucial goals for water providers in times of limited supply. It reduces demand by increasing water tariffs, but still allows consumers' choice over water usage based on opportunity cost, rather than simply prohibiting use over an arbitrary level. Importantly, TDP also maintains revenue streams to facilitate the development of new water supply infrastructure. A TDP can be a multiplier to levy to the business-as-usual single or multiple block tariff arrangement of the water business and be designed to ensure that short-term demand reductions by consumers in periods of drought are revenue neutral or positive to achieve the water supply planning objectives of the water business.

This research utilises a TDP to create a holistic model, with new infrastructure transparently funded and consumer demand interactions demonstrated. This enables the best pricing approach to be identified under simultaneous demand management and diversified water supply portfolio investment.

\subsection{Resource and infrastructure utilisation}

The poor utilisation of desalination plants has been greatly lamented (Killoran, 2013a). When producing potable water from seawater, desalination plants have high energy intensities (energy consumed in water supply), which have consequences for electricity production and associated greenhouse gas emissions (Hoang et al., 2009). If desalination plants are required to augment surface water supply in SEQ, the following must be considered: how can their construction and operation be optimised to increase water security whilst limiting the negative consequences associated with their operation?

A potential means of addressing the high energy intensity of traditional desalination plants is the continuing development of pressure retarded osmosis (PRO) technology, which could significantly enhance community perceptions towards and lower the life cycle costs of desalinated water. The conundrum facing government and water businesses is that in above rainfall periods when dam levels are full and potentially overflying, their portfolio of desalination plants have limited value and are put to standby mode. The use of dual-purpose membrane technology would allow desalination plants to generate electricity through PRO when not being used for potable water production (Helfer et al., 2013). Currently desalination plants consume 3-4 $\mathrm{kWh} / \mathrm{m}^{3}$ when producing freshwater from seawater (Hoang et al., 2009). Thorsen and Holt (2009) report that up to $0.74 \mathrm{kWh} / \mathrm{m}^{3}$ can be generated from mixing seawater and freshwater at $20 \mathrm{C}$, while successful trials of PRO technology have occurred in Norway (Achilli and Childress, 2010). Helfner et al. (2014) provide a recent comprehensive review of the PRO technology trends, benefits, impacts and economic aspects. While they conclude that PRO technology is viable, they mention a number of barriers to its widespread commercial development, particularly the high cost of PRO membranes. Nonetheless, with further development and pilot plants using PRO technology, such membrane costs will likely reduce exponentially as they have done for traditional RO technology used for desalination. In summary, although further investigations are still needed to ensure PRO technology is viable, technical advances in desalination technology are promising for being a viable alternative for renewable energy production. 
Essentially, the seasonal abundance of freshwater can be utilised to create energy through the PRO process. This renewable energy production could help to offset the energy consumed in RO and would represent far more efficient utilisation of infrastructure. As part of the integrated SDM, the potential benefits of this technology, and how it might operate alternately with RO desalination, can be evaluated.

\subsection{Effectively modelling the socio-environmental system}

Existing models cannot adequately assess a range of water governance alternatives (Barker et al., 2010) as they focus on meeting set levels of demand under engineering constraints, utilising supply-side models (Hughes et al., 2009). Hughes (2008) and Grafton and Ward (2008) allow demand to respond to prices through the use of endogenous demand curves.

Water resource systems are characterised by many interdependent components that together produce various economic, environmental, ecological and social impacts (Loucks and van Beek, 2005). Environmental systems also contain feedbacks and discontinuous non-linear relations (Kauffman, 1993; Patten and Jørgensen, 1995). Water systems, like most complex environmental matters, are highly dynamic and consist of many feedbacks and interdependencies between their elements. Hence, simulation is a potentially effective method of exploring potable water supply and demand futures, based on differing behavioural assumptions, including reaction to price mechanisms and quotas. In this context, System Dynamics (SD) modelling offers a suitable platform for exploring complex water systems. Therefore, in this research, the SD modelling approach is employed to investigate the water system in SEQ as well as to conduct scenario analysis.

System dynamics is an approach to understanding the behaviour of complex systems over time. It deals with internal feedback loops and time delays that affect the behaviour of the entire system. Feedback loops are the basic structural elements of dynamic systems that reflect a chain of causal relations among the interacting components of a system. More formally, a feedback loop is a closed sequence of causes and effects, or, a closed path of action and information (Kirkwood, 1998). These loops are often linked together and display nonlinear relationships that often cause counterintuitive behaviour (Forrester, 1996). The evolution in the field, signed by works in urban dynamics (Forrester, 1969), and large scale experiments on world dynamics (Forrester, 1971), (Meadows et al., 1972) was a starting point for the development of softer approaches that lead to the formalization of systems thinking, to overcome issues in simplifying complex realities with numerical models. In parallel to softer approaches, system dynamics models have evolved and are used today to simulate complex systems behaviour in public health (Cavana and Clifford, 2006; Homer et al., 2007); energy and the environment (Fiddaman, 2002; Ford, 2005; Sterman, 2008) irrigation systems and water quality (Gharib, 2008; Zhang, 2008); climate change impact assessment and adaptation modelling (Franck, 2009; Sahin and Mohamed, 2009; Sahin and Mohamed, 2013) and many other fields. 
To simulate the water resources system in SEQ, a SDM was developed using Vensim® DSS (Ventana Systems, 2012). Key variables were identified, with relationships between these variables assumed and parameterised. A participatory modelling approach was utilised to maximise accurate replication of system structure so that modelling would reveal system behaviour, which is often far from what initial intuition would suggest (Vennix et al., 1996; Van den Belt et al., 2004; Langsdale et al., 2009). The research team has engaged with a range of experts from academia, private consultants and government water bodies to inform model development. A systems approach allows integration between supply, demand and asset management.

The SDM is composed of three sub models which simulate demand, supply, and asset management within the SEQ water resources system. Large interdependencies exist between these components. The SDM facilitates a time based exploration of the effects of altering multiple variables concurrently (e.g. increased dam capacity, rain-independent supply source construction, climate change, population growth, TDP). The platform provides crucial visualisation of system interaction over time, allowing unexpected feedbacks to be identified. Models of socio-environmental systems with many sub models are often hard to understand for those not involved in their construction (Polhill and Gotts, 2009). Hence, this visualisation is an important tool for communication with stakeholders and decision makers, lest this research be confined to academic circles.

The evaluation requires the use of multiple, complementary methods to identify any shortfalls in the data, the theory, and the methodology. However, there is no consensus among modellers as to what the methodologically correct guidelines or procedures for evaluating simulation models should be. Furthermore, a number of researchers have raised concerns regarding model testing and evaluation. For example, Oreskes (2004) states that verification and validation of numerical models of natural systems is impossible as these systems are never closed, and because model results are always non-unique. Instead, models can be confirmed by the demonstration of agreement between observation and prediction. Although it is difficult, nevertheless, the evaluation of all models is important. To overcome these difficulties, Sojda (2007) proposed an evaluation approach, which includes: (1) testing model performance against a preselected standard; (2) use of real-time and historic datasets for comparison with simulated output; (3) use of panels of experts judiciously; (4) sensitivity analysis of system outputs in relation to inputs; and (5) examining major components when the validation of a complete system is impossible to recognize potential pitfalls.

More recently, Bennett et al. (2013) suggested a five-step performance evaluation procedures for effective use of environmental models, these are: (1) re-assessment of the model's aim, scale and scope; (2) characterisation of the data for calibration and testing; (3) visual and other analysis to detect under- or nonmodelled behaviour and to gain an overview of overall performance; (4) selection of basic performance criteria; and (5) consideration of more advanced methods to handle problems such as systematic divergence between modelled and observed values.

In our research, the model evaluation flowed through a multi stage process, including: 
1) Engaging expert stakeholders throughout model process: To achieve adequate robustness of the simulation model, a number of models were developed, tested, and modified before the final model was confirmed. Throughout the modelling process, stakeholders consultation was used to assess the validity of the major components of the model through seeking agreement about various modelling aspects, such as: modelling scope and purpose; a simulation model setup including a model boundary selection; data collection for the study area; and, modelling logic (i.e. parameter relationships); and ensuring the model output adequately reflects the real situation. Continuous involvement of expert stakeholders in the model building and testing significantly improved the value of the resulting model in terms of its usefulness. This was an important step to test whether the proposed model was realistic and successful at addressing its intended purpose.

2) Use of historic datasets for parameter validation (inspecting the output of the simulation by comparing the past results): The parameter validation was used to obtain the values for the parameters by using randomly generated data based on historical data. Initial testing was conducted by comparing the model to the data collected for the study area to test the model behaviours. Once the model behaviours were close enough to represent the system, it was deemed appropriate for use in further analyses.

3) Comparing model output with the findings of SEQ Water strategy report. As Huggett (1993) suggests, it is sound practice to test the validity of a model by comparing its prediction with independent observations made in the field or laboratory. Thus, in the current study, the modelling findings of SEQ water utilities reported in QWC (2010) report was used as the validation model to compare the output of our model.

4) Visual analysis: By running the model to visual the display of the model output, and observing whether the behaviour satisfies the logic of the model.

5) Finally, to gain more confidence in the behaviour of the model, a sensitivity analysis was performed by changing the assumptions about the value of the constant variables, as well as examining the resulting output. The model contains a range of constant variables. To examine their effects on the simulation output, the values of three constants variables were chosen and modified: Population growth rate, per capita water demand, and demand elasticity as these variables directly affect water supply and demand balance, and needs for new infrastructure investment.

\section{SYSTEMS MODEL DEVELOPMENT AND EXPLORATORY SCENARIOS}

Voinov (2008) explains that when a model can effectively take into account the essential features of a real-life system, its behaviour under stress will likely be similar to the behaviour of the prototype model. Essential variables for model operation were identified by reviewing locally based literature for region specific inputs and examining world literature for more generic variables and their behaviour. System norms 
and rules were informed by the SEQ Water Strategy Reports in combination with other literature (QWC, 2010, 2012b).

\subsection{Supply sub model}

The supply sub model considers volumetric supply from both rain-dependent and rain-independent sources of water (Figure 2). As a starting point, the SEQ water grid currently contains one desalination plant and one purified recycled water plant, which account for only $3.5 \%$ of the combined storage reserve (QWC, 2010, 2012b). Rain-dependent supply is driven predominately by surface water storage supply and to a lesser extent groundwater pumping, which are highly influenced by climatic conditions and increasingly more by climatic change as the century progresses.

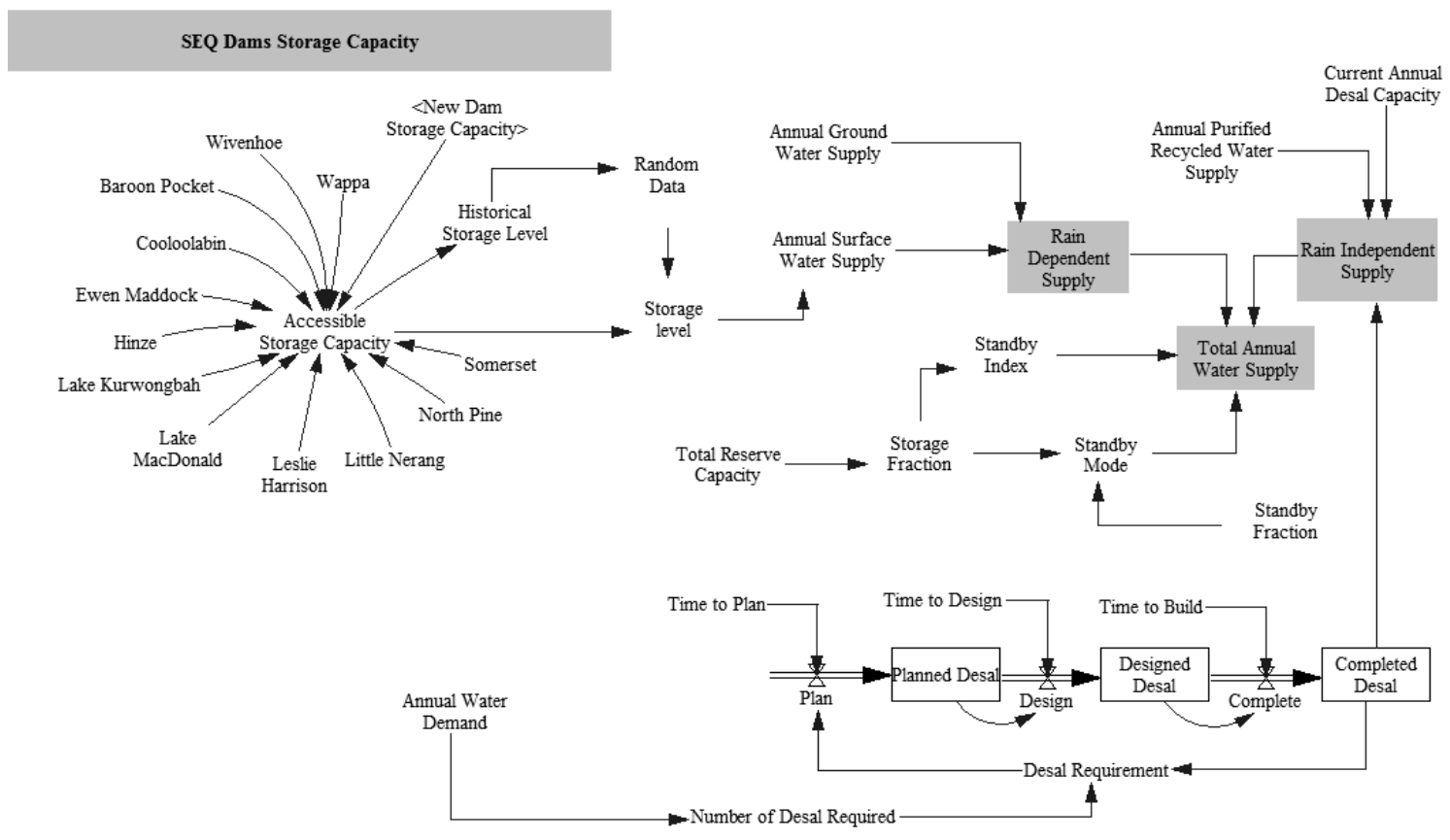

Figure 2. SEQ grid connected regions' water supply sub model stock and flow diagram.

It is essential to use meaningful data to obtain meaningful results. Therefore, for each time period, surface water inflow data is randomly generated based on historical data published in the SEQ Water Strategy reports using a triangular distribution. This approach provided a future inflow prediction forecast that resembled characteristics of historical records. However, one must note that future rainfall patterns are likely to be different due to climate variability and also uncertainties in future climate in the region. Additionally, the impacts of La Nina and El Nino seasons on inflows to dams are taken into account in generating random inflow data, and total inflow is capped to the maximum storage level of each dam. A special feature of the supply sub model is that has an optional function where it can trigger the planning, design and construction of new augmented rain-independent supply sources to the bulk supply portfolio (i.e. desalination plants for this study as it is the most likely rain-dependent supply source to be used in the coastal SEQ region), when 
rain-dependent supplies are at critical threshold levels. When the available supply falls to below $60 \%$, the planning for a new desalination plant begins, followed by designing and construction, only pausing if the level goes above 60\% (QWC, 2010). Moreover, the supply sub model is able to switch the existing portfolio of rain-independent supply sources to different operating capacities or even standby when surface water supplies are plentiful. For example, when surface storage capacity is above $80 \%$, rain-independent supply sources are placed on standby to reduce the supply cost. When the storage level drops below an $80 \%$ level, then this supply become active and adds water to the grid.

\subsection{Demand sub model}

The water demand sub model estimates Annual Water Demand, which is driven by three key variables: population, per capita water demand and climate impacts. These are calculated using the following equations:

$$
\begin{aligned}
& \mathrm{AWD}=\mathrm{P} \times \mathrm{WD}_{\mathrm{pc}} \\
& \mathrm{P}=\int\left(\mathrm{P}_{\mathrm{Ch}}\right) \mathrm{dt}+\left[\mathrm{P}_{\mathrm{i}}\right] \\
& \mathrm{WD}_{\mathrm{pc}}=\mathrm{WU}_{\mathrm{pc}} \times\left(\mathrm{C}_{\mathrm{I}}\right)
\end{aligned}
$$

Where:

$$
\begin{aligned}
& \text { AWD: Annual Water Demand } \\
& \text { P: Population } \\
& \mathrm{P}_{\mathrm{Ch}} \text { : Population Change } \\
& \mathrm{P}_{\mathrm{i}} \text { : Initial Population } \\
& \mathrm{WD}_{\mathrm{pc}}: \text { Per Capita Water Demand } \\
& \mathrm{WU}_{\mathrm{pc}} \text { : Per Capita Water Use Projection } \\
& \mathrm{C}_{\mathrm{I}}: \text { Climate Impacts }
\end{aligned}
$$

Figure 3 illustrates the basic dependencies of these variables, and others within the demand sub model. The rate of population growth and the magnitude of price change strongly influence both supply and demand over time. Therefore, in this research, to estimate the future population, two growth rates, namely the current $2 \%$ and the projected 1.5\%, were used (Queensland Treasury, 2011). Three demand levels were considered to represent the most likely future scenarios for water usage. First, the current low levels of per capita consumption $(200 \mathrm{~L} / \mathrm{p} / \mathrm{d}$ residential and 100 industrial/other $\mathrm{L} / \mathrm{p} / \mathrm{d}=300 \mathrm{~L} / \mathrm{p} / \mathrm{d})$ which have resulted from years of restrictions being used. Next historical pre-drought demand was found $(300+150=450 \mathrm{~L} / \mathrm{p} / \mathrm{d})$, while the third level was derived from the SEQ Level of Service objectives $(230+145=375 \mathrm{~L} / \mathrm{p} / \mathrm{d})(\mathrm{QWC}$, 2012b). Demand can also be affected by the water price. In this study a Temporary Drought Price (TDP) was applied in periods of water scarcity with the dual purpose to reduce demand and also provide sufficient 
additional revenue to fund capital intensive rain-independent bulk water infrastructure. In this study, a mean elasticity value of -0.51 was applied with a range of -0.3 to -0.8 allowed in the SD, after a critical review of the literature (Hoffmann et al., 2006; Olmstead et al., 2007; Frontier Economics, 2008; Grafton and Ward, 2008). It must be noted that the price elasticity values used in this model are more reflective of the long-run analysis of water demand during longer drought periods.

The year-to-year wet/dry seasonal variation that occurs, results in a short-run elasticity of demand with much smaller elasticity values. Since the model is examining long-term strategic planning implications and not short-term fluctuations, elasticity has only been considered in the demand function for water use of longrun behaviour. Specifically, the price increase impact has been calculated by using the Time to Price Adjust variable, which adjusts the demand progressively over a period of time (i.e. 2 billing periods). Readers should note that for all major input variables such as demand elasticity, the system model has a dashboard which allows users to assign a value within a range instead of just a single value in order that a range of scenario outcomes can be explored. A full discussion on the application of the TDP is discussed in the results section of the paper.

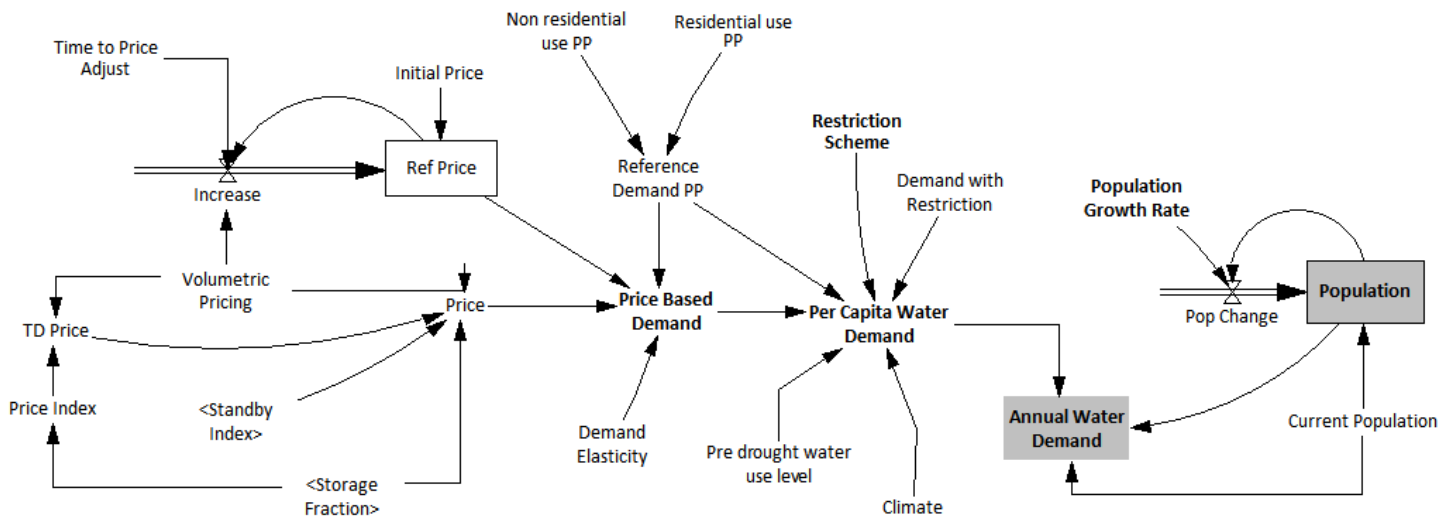

\section{Figure 3. Demand sub model stock and flow diagram.}

\subsection{Asset management sub model}

The asset management (financing and resource utilisation) sub model is designed to reveal how water governance decisions can act to close the supply gap and provide water security insurance. This is primarily accomplished through the use of desalination plants, with limited availability of new dam sites in SEQ (QWC, 2010). The financial branch of the model considers monetary interactions and requirements. The resource utilisation branch is used to maximise utilisation of the desalination plants and minimise the net energy requirements for their operation.

The model takes the Annual Water Demand, less that supplied by surface water, and calculates the revenue generated from the required desalinated water production, as shown in Figure 4. When desalination 
plants are functional for water manufacturing, their energy requirements are calculated. When they are not needed for RO, they perform forward osmosis (FO) through PRO, generating energy.

The capacity of future desalination plants is assumed to be the same as the existing Tugun desalination plant (50,000 ML/year). However, in order to examine the impact of larger plants, this can be adjusted before or during the simulation. When desalination plants are not in use for water production, the model switches their function to PRO, generating renewable energy.

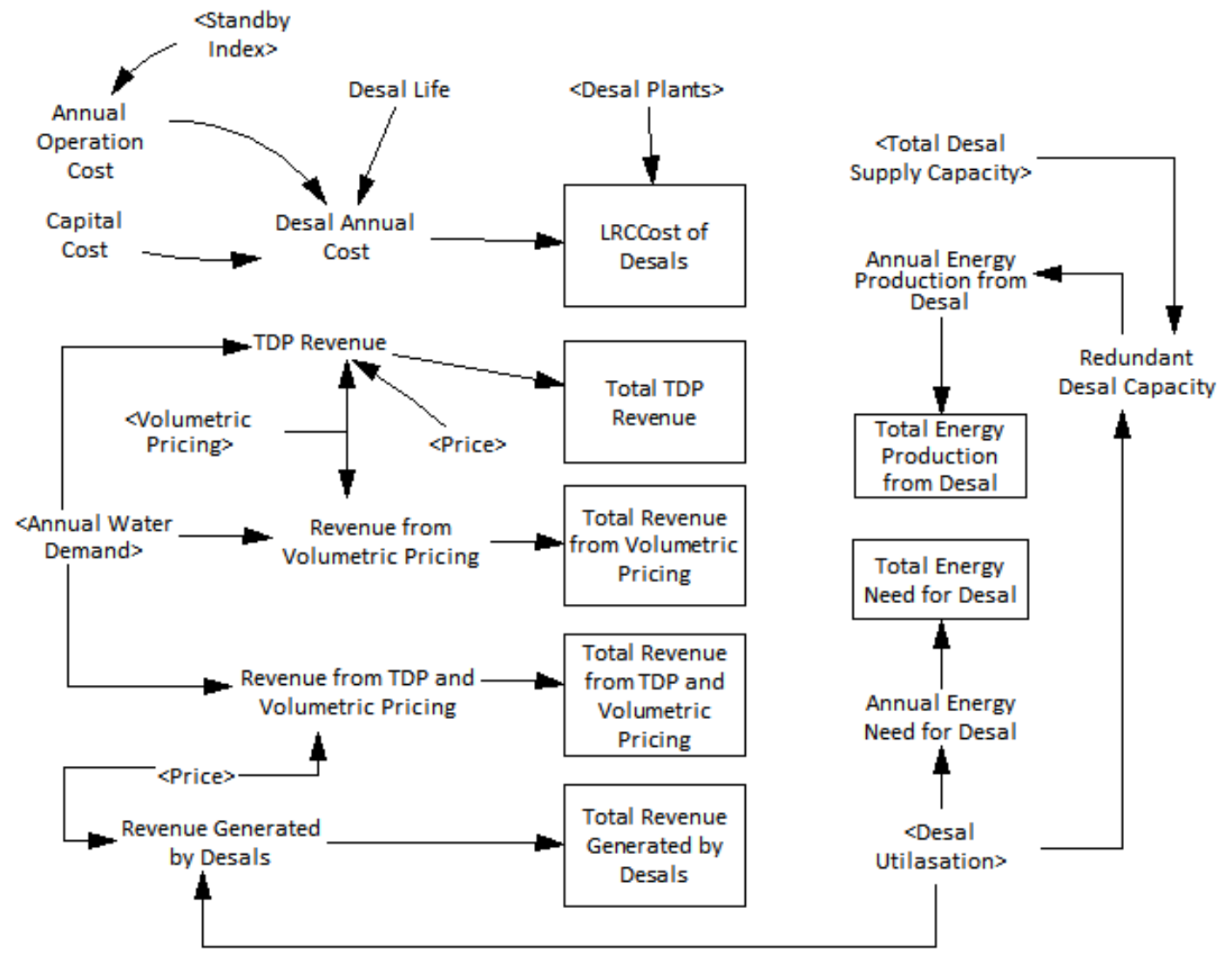

Figure 4. Asset management sub model stock and flow diagram.

\subsection{Scenarios}

A key intention of model development was to allow flexibility, rather than limit users to predefined scenarios. Thus the SDM is capable of simulating a very large number of permutations, based on user choice and the multivariate Monte Carlo simulation technique. For the purposes of this paper, five prescribed scenarios are considered, to demonstrate the effects of exogenously driven systemic change to the socioenvironmental system, and how endogenously driven change to water governance can deal with these changes. Findings from the modelling scenarios are presented in the next section. 
Table 1. Predefined input values for examined simulation scenarios.

\begin{tabular}{lcccc}
\hline \multicolumn{1}{c}{ Scenarios } & \multicolumn{3}{c}{ Scenario Description } \\
\cline { 2 - 5 } & $\begin{array}{c}\text { Population } \\
\text { Growth (\%) }\end{array}$ & $\begin{array}{c}\text { Water Use } \\
\text { (L/Person/Day) }\end{array}$ & $\begin{array}{c}\text { Desal in Use } \\
\text { (Yes/No) }\end{array}$ & $\begin{array}{c}\text { TDP Pricing } \\
\text { (Yes/No) }\end{array}$ \\
\hline BAU & 1.5 & 300 & No & No \\
$\begin{array}{l}\text { Business As Usual } \\
\text { BAU R \& D }\end{array}$ & & Varying & Yes & No \\
$\begin{array}{l}\text { Water Restrictions (Level 1 to Level 5) } \\
\text { BAU \& D } \\
\text { Business As Usual with Desal } \\
\text { BAU \& TDP }\end{array}$ & 1.5 & 300 & Yes & No \\
$\begin{array}{l}\text { Business As Usual with TDP } \\
\text { BAU D \& TDP } \\
\text { Business As Usual with Desal and TDP }\end{array}$ & 1.5 & & No & Yes \\
\hline
\end{tabular}

\section{MODELLING SCENARIO RESULTS}

\subsection{Forecasts for water supply and demand}

$1.5 \%$ population growth sees the SEQ population rise to 4.13 million by $2031,5.57$ in 2051 and 13.6 million by 2110 . Annual Water Demand is highly sensitive to population growth, per capita water use and climate variability. For fluctuating population growth between 1.5 and $2 \%$, and varying per capita demand as outlined in the previous section, Annual Water Demand ranges from 1.86 million ML/year to 3.65 million ML/year at the end of the 100 year simulation. 30 years from today, the minimum expected water demand level is equal to $30 \%$ of the current SEQ accessible storage capacity, while maximum demand level would account for $45.2 \%$.

Two supply scenarios were tested and are compared in Figure 5. The simulation results show that even when a 10 per cent increase in the current accessible water storage capacity is considered (i.e. 2,220,000 ML to 2,442,000 ML) the current water supply portfolio will still not be sufficient to meet annual demand due to high inflow variability and a growing water demand in the SEQ region.

As the system moves past 40 years into the future under high demand, the present portfolio of water storages is inadequate, depleting very rapidly to critically low levels, leaving the region at high risk of supply failure. As outlined in the SEQ Water Strategy (QWC, 2012b) the drought storage reserve is supposed to provide, in conjunction with climate resilient sources, a minimum of 36 months' supply of water at a restricted demand. In this model, the drought storage level is calculated based on annual demand without restriction. This emphasises the need to investigate new water governance options. The systemic change brought about by population growth and decreased surface inflows cannot be mitigated. Thus, the system must be reorganised, or forced to operate under new rules, in order to cope. 


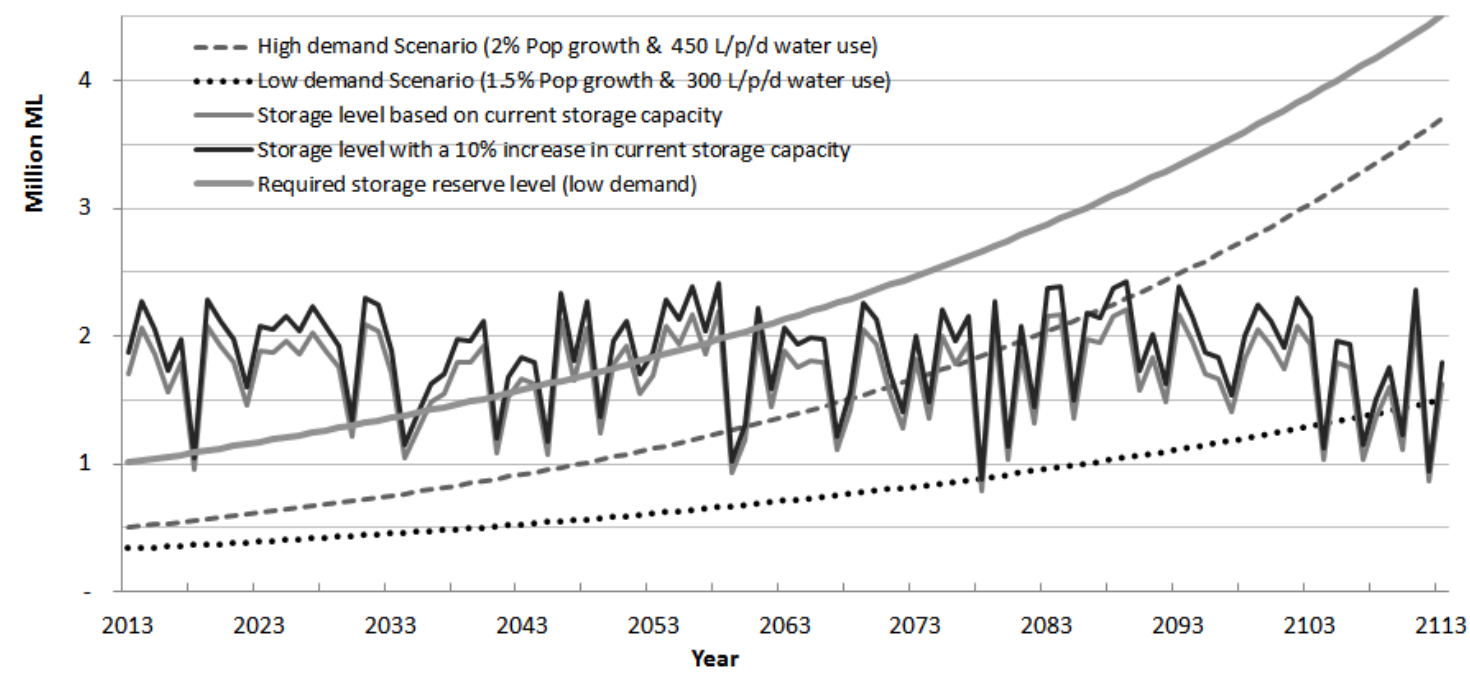

Figure 5. Combined storage level and water demand for scenarios examined

\subsection{System simulation under reformed governance}

TDP is considered in two scenarios as shown in Table 1. The SDM simulates the impacts of changing prices and TDP on demand, supply, revenue and the costs of construction of new desalination plants. TDP is only initiated during drought periods when water resources are becoming scarce. The TDP escalation above the base price level is linked to the available storage or supply level (i.e. TDP escalation to base water price starts at $60 \%$ supply fraction). As the storage level falls below the threshold level for TDP initiation, it increases the normal water price between 10 and $300 \%$ at certain critical levels. Similarly, as the total storage level restores to more secure levels due to above average rainfall or the commissioning of newly constructed desalination supply, the TDP levy is withdrawn at the same trigger points. Using the SDM, the impacts of TDP on revenue over the 100 year period timeframe were also simulated. During the simulation, the TDP is only enacted during drought periods when water availability is becoming increasingly scarce. We found that, if used, the TDP would generate additional revenues of about $\mathrm{A} \$ 4.2$ billion over the course of the simulation period. This additional revenue would be sufficient capital to build four new desalination plants with a total capacity of 200,000 ML/year. Moreover, the TDP provides a mechanism to generate additional revenues to fund water supply infrastructure much closer to the capital investment period than would be the case under current planning practices where long-term price rises and debt are used to fund such large capital investments.

Since the purpose of the TDP is to achieve the water restriction demand management target through pricing, it is reasonable to use the existing restriction trigger points and targets for determining the TDP level. Therefore, the demand restriction targets were used to determine the extent of TDP that would be required to achieve a similar demand reduction if the restriction scheme were replaced with an alternative pricing scheme (i.e. TDP in this study). The herein adopted TDP assumptions are consistent with the restriction trigger points described in SEQ Water Strategy reports (QWC, 2010, 2012b). For example, in the SEQ 
System Operating Plan 2012 (QWC, 2012a), medium level restrictions are defined as a targeted reduction in consumption of 15 per cent below the total consumption volume in normal operations, triggered when all key water grid storages reach 40 per cent of the combined total water storage capacity of these storages. The model achieves this equivalent restriction target by using a certain price level achieved through the addition of the TDP to the existing bulk water price and an average demand elasticity of -0.51 in order to calculate the equivalent reduction in water demand.

The BAU TDP scenario considers TDP in isolation, while the BAU D \& TDP considers TDP in conjunction with the construction of new desalination plants. These scenarios are compared in Figure 6 below.

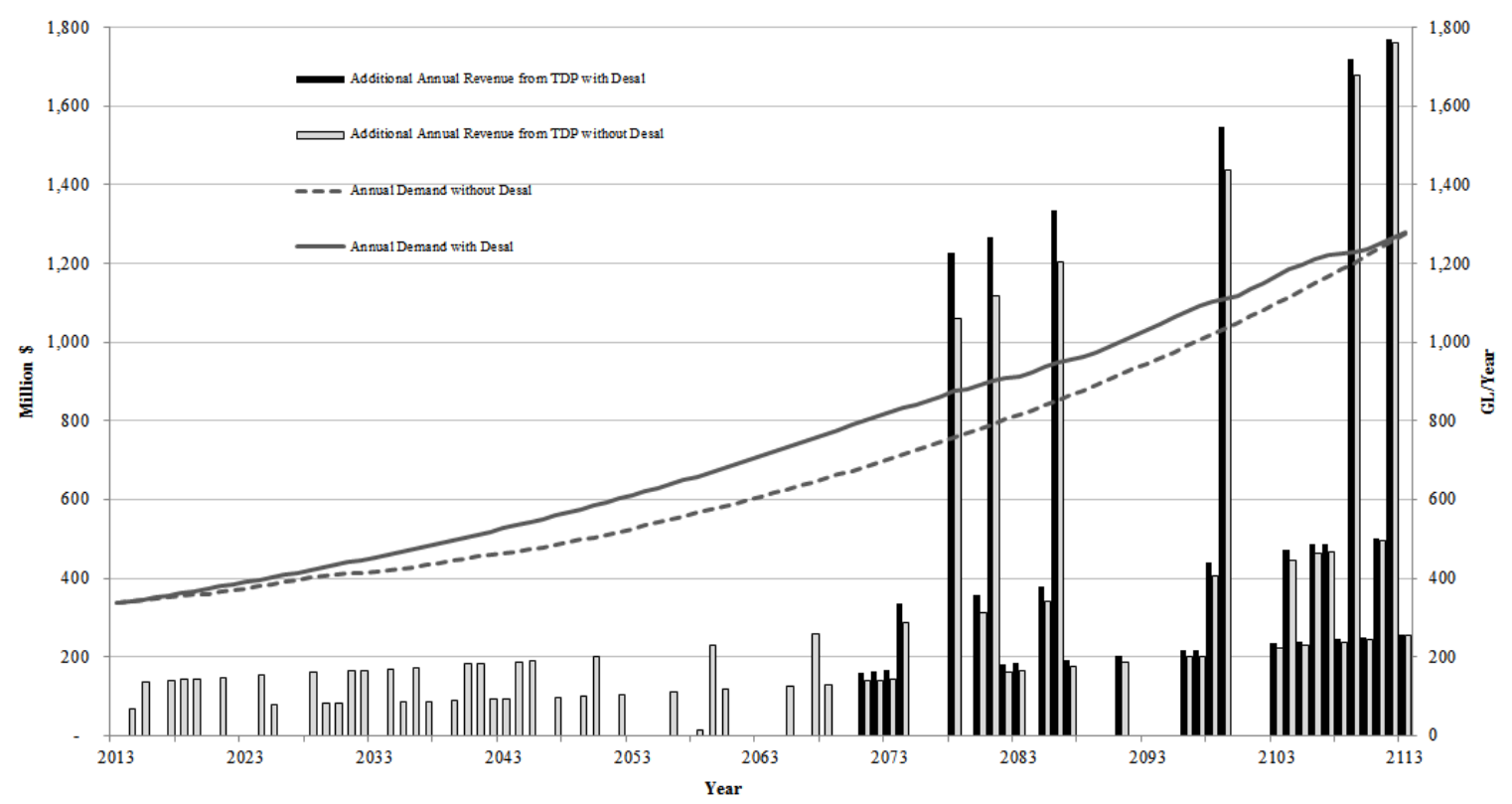

Figure 6. Comparison between BAU TDP and BAU D \& TDP scenarios in terms of demand and TDP generated revenue

TDP alone is displayed as effective in reducing the demand for water, preventing supply demand gaps and limiting demand to under $1.3 \mathrm{GL} /$ year at the end of the simulation period. However there are fundamental problems with this strategy of pricing water scarcity but then not acting to provide the necessary additional supply to alleviate future drought periods. Moreover, for this scenario, water demand is reduced further and further as water security in SEQ falls in the face of a rising population and decreasing inflows. This would inevitably lead to public unease and sustained intense political pressure, with the region being constantly in a water crisis. In essence, TDP alone is containing the current problem by preventing total supply failure, but not increasing the system's ability to avoid similar crisis reoccurring in the future. The sustained reductions in revenue due to low demand would also limit the funds available to water governance bodies for investment, thereby creating a vicious cycle. The resources required to prevent future crisis must be sourced before the crisis begins; this is a fundamental argument of this study. 
The BAU D \& TDP scenario, which simultaneously reduces demand in periods of water scarcity while concurrently planning, designing and constructing rain-independent sources to the water supply portfolio, removes the issues that arise from a standalone TDP. Initially there is no TDP revenue as the desalination capacity prevents the need for price increases with added water security. When a TDP is eventually initiated in year 58 due largely to the momentum in population growth, more TDP revenue is generated than in the BAU TDP scenario, because demand is greater in magnitude.

As the model moves into the second half of the analysis period, SEQ's population becomes so large that the planning and construction of 50,000 ML/year desalination plants cannot keep up with the growing demand for water. Thus, the region is consistently in water crisis with very high prices under TDP. This indicates the need for either a very large surface water addition to the SEQ water grid, or the construction of a high volume manufactured water facility (e.g. >500,000 ML/year). The BAU D \& TDP scenario sees the new water governance measures function effectively for approximately 60 years.

\subsection{Potential of PRO integration to system}

The proposed endogenous changes originating in the human system, namely the construction and operation of desalination plants to augment surface supply, risk creating feedback that propagates back to increase the driving exogenous environmental component of the systemic change (reduced stream flows). As the RO desalination is highly energy intensive, the future production cost of desalinated water will be heavily influenced by the cost of plant construction and the anticipated increasing cost of energy (Hoang et al., 2009). This may be partly offset by improved utilisation efficiencies of desalination plants. With this in mind, a branch of the model incorporates the utilisation of dual-function desalination plants that utilise both traditional RO and new-age PRO technology.

Clearly, it is important to explore whether the unit capital cost $(\$ / \mathrm{kW})$ and operating cost to generate energy $(\$ / \mathrm{kWh})$ from PRO technology plants are viable. Investigations of a power plant with PRO at the Great Salt Lake by Loeb (2001) reported that a PRO plant could produce $66 \mathrm{MW}$ at a capital cost of US\$ 9,000 and an energy cost of $0.09 \mathrm{US} \$ / \mathrm{kWh}$. This cost includes the capital amortisation (0.058 US $\$ / \mathrm{kWh})$, membrane replacement $(0.008 \mathrm{US} \$ / \mathrm{kWh})$, labour $(0.008 \mathrm{US} \$ / \mathrm{kWh})$, and operation and maintenance cost (0.017 US\$/kWh). This cost, as reported by Achilli and Childress (2010), is comparable to the average retail electricity price in the United States at that time (0.067 US\$/kWh).

The utilisation of desalination plants is controlled by a logic relationship, mirroring the actions of a water governance body (QWC, 2010; SEQ Water Grid, 2011; QWC, 2012b). In some cities, local governments define rules linked to dam storage levels that determine when and how water utilities can operate their desalination plants (i.e. standby, fractional operation, full capacity operation). For example, as stated in the SEQ Water Grid (2011) report, the existing desalination plants in the region will be operated at capacity when key water grid storages are below $60 \%$ of combined capacity, which may be further increased. In 
Sydney, on the other hand, interim desalination plant operating rules requires the plant operate at full capacity when the total dam storage level firstly dips below $70 \%$ and continues operating until the total dam storage level reaches $80 \%$. Therefore, the desalination plants with higher supply level trigger points reduce the probability of the rain-dependent supply sources reaching low levels, causing restrictions and further augmentations to the supply systems (Frontier Economics, 2011). However, the drawback of such higher trigger points is that bulk water utility operators have less dam capacity available for high rainfall events. In this research, the desalination plant is triggered at $80 \%$ combined dam levels, thereby satisfying both regions' operation rules. It would of course be counterintuitive to utilise desalination plants to generate electricity in times of water shortage, as this would further contribute to water scarcity. When dam levels are in excess of $80 \%$ capacity, desalination plants are used for energy production. During La Nina years, dam inflows are typically high, leading to redundant water behind dams, overflows, and stronger stream flows below dam walls. The SEQ regions sub-tropical climatic conditions are highly suitable for a dual-function desalination plant.

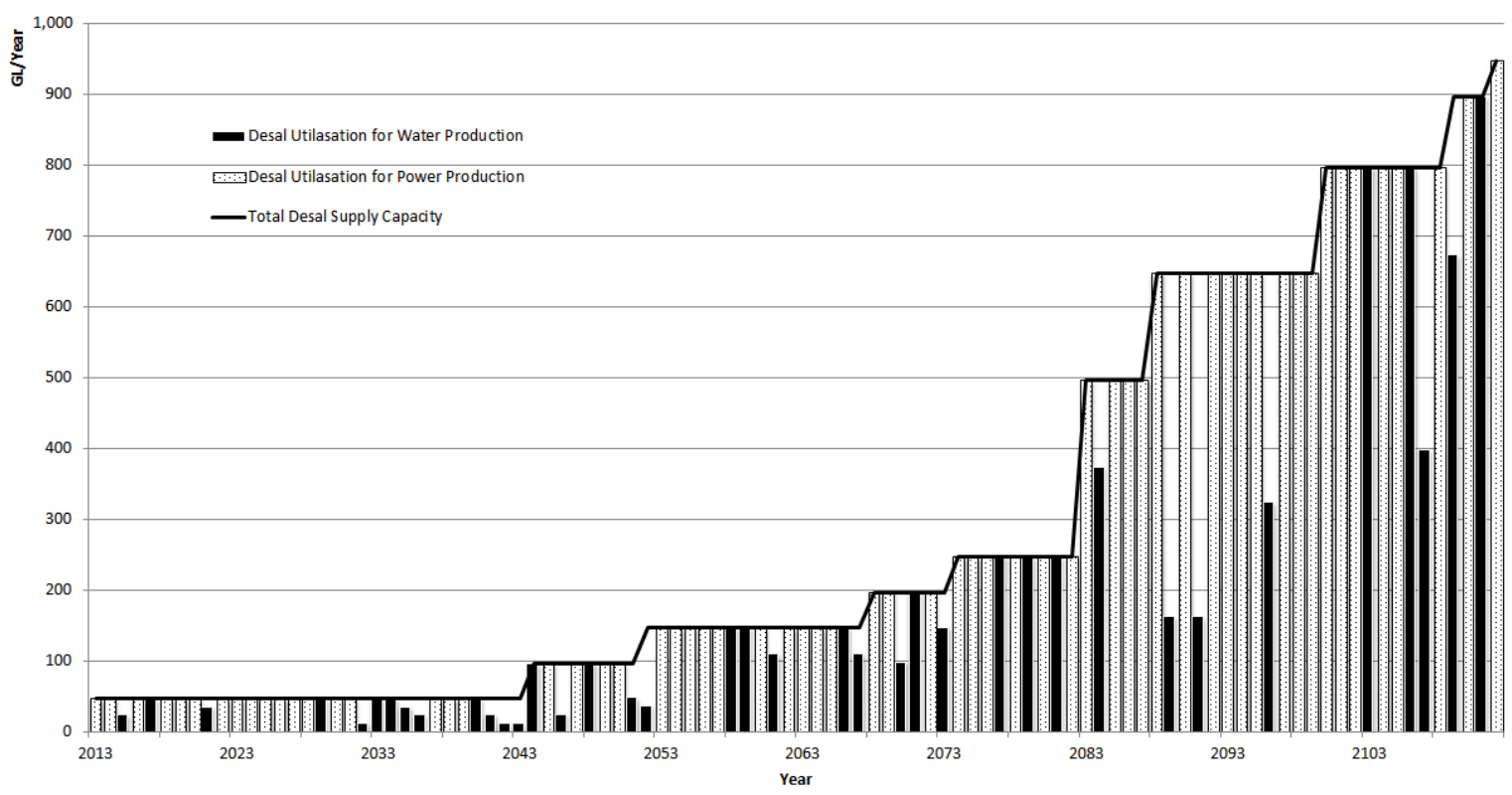

Figure 7. Utilisation of desalination plants for water production and power production over the simulation period

As illustrated in Figure 7, the model reveals that over the 100 year simulation period RO desalination accounts for $25 \%$ of the total possible utilisation available, while PRO accounts for a higher $66 \%$. The remaining times of non-utilisation (i.e. 9\%) occur in years where only a portion of full plant capacity is required for RO desalination to augment water supply. As mentioned above, it would be counterproductive or technical unfeasible to use the remaining plant capacity for PRO in these years. In terms of infrastructure utilisation, this represents a $91 \%$ utilisation efficiency, with non-utilisation only accounting for $9 \%$ of total available utilisation for the 100 year period. Given that traditional single-purpose RO desalination plants 
would only have an average utilisation fraction of $25 \%$ over the 100 year period examined due to the variability in dam inflow, this is a sensible option for the region.

Now the utilisation potential is clear, the focus shifts to how much energy can be produced in the power production periods, and how does this compare to the energy consumed when RO desalination is active.

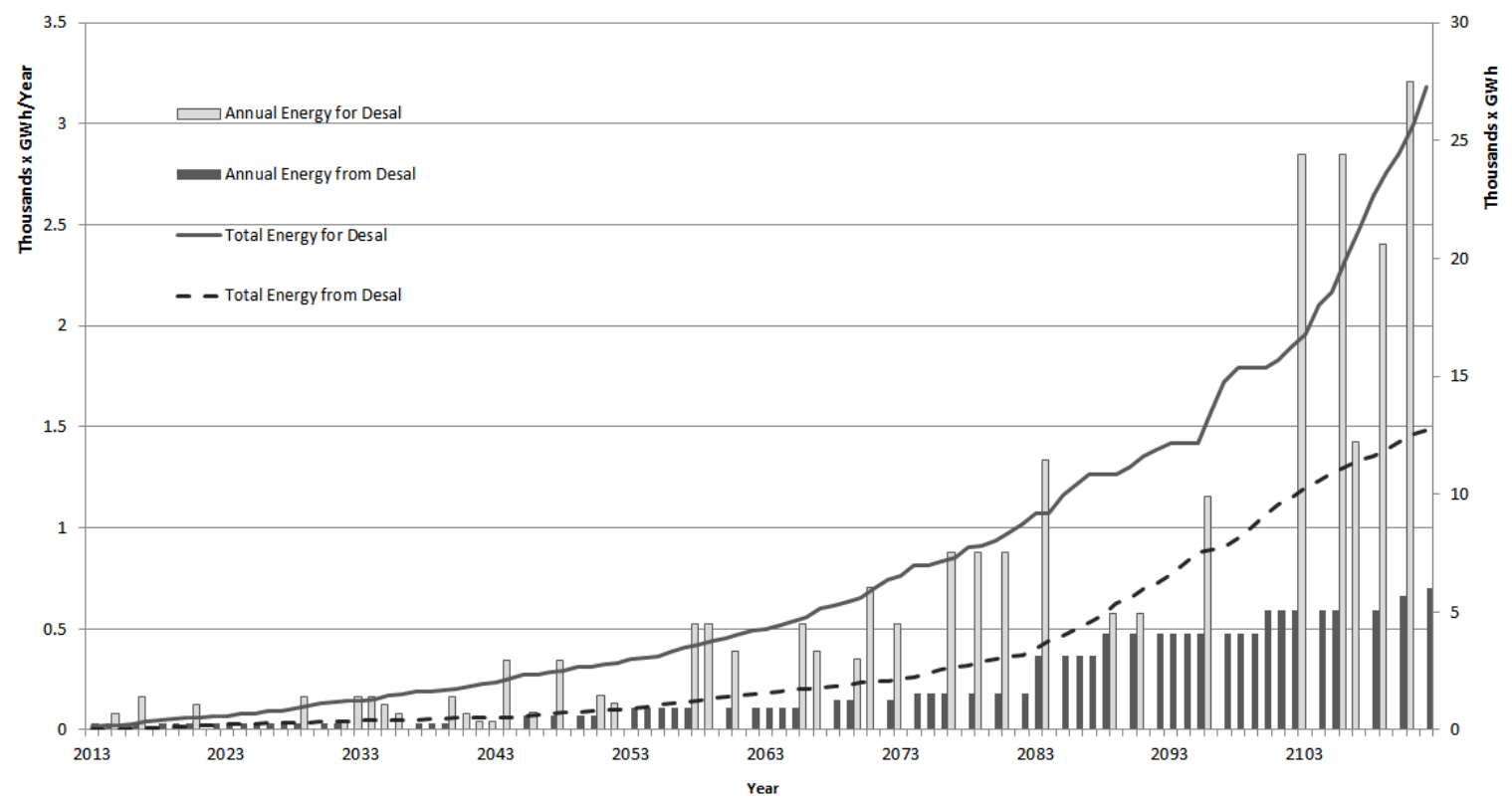

Figure 8. Annual and cumulative energy demand and energy produced from desalination plants in SEQ over the simulation period.

For visualisation, the Annual Energy for Desalination represents the annual consumption rate in place during the final time step of each year. The decision making process for switching between energy consumption or production (i.e. RO or PRO) occurs on a quarterly basis in the model, with the Total Energy for Desalination calculated from the sum of these intervals. Using the efficiency rates outlined in Section 2.3, the SDM reveals that over the 100 year time period that PRO generates $47 \%$ of the energy consumed in water production. This would be a very significant reduction in the net energy demand and associated carbon footprint if such dual-function water manufacturing plants are constructed instead of traditional RO limited plants.

As the simulation progresses, the percentage of energy generated relative to energy consumed rises steadily, from $25 \%$ after 5 years, to as high as $60 \%$ after 90 years. In the final 10 years of the simulation the desalination plants are almost constantly forced to augment water supply as TDP is in place for the dry season each year. Even when reservoirs fill with substantial rains, the population is so large that these reserves are quickly depleted. 


\section{DISCUSSION}

\subsection{Diversifying the traditional rain-dependent water supply portfolio}

As set out by the SEQ Water Strategy (QWC, 2010, 2012b), the drought storage reserve is defined as the stock of water below $60 \%$ of the working capacity of the region's working water supply capacity. This is the current means for the system to deal with uncertainty over adverse short to medium term climatic conditions. The drought response plan states that the drought storage reserve, in combination with rain-independent supply, must provide at least 36 months' supply under water restrictions. This reserve level is already a high proportion of total capacity, and with population set to increase, and inflows set to decrease, this method for dealing with uncertainty in the system will become increasingly inappropriate.

Under the BAU D and TDP scenario, the supply portfolio changes, with an increase in the proportion of rain-independent supply. Logically, this increase (neglecting other system changes) would allow the volume of the drought storage reserve to decrease as more desalination plants are constructed. In the SDM, the drought storage reserve is calculated considering the Proportion of Desalination in the total supply capacity. Higher proportions of desalination or other rain-independent supply sources serve to reduce the drought storage reserve level required as these sources are dependable.

Starting at 3.5\%, the simulation results show that the proportion of desalinated supply increases to $40 \%$ at the end of the 100 year period. This allows the required minimum storage reserve level to drop from 36 months' supply to 22 months' supply (995,000 ML/Year). This strengthens the system's ability to deal with uncertainty by utilising desalination plants as an insurance policy. Region climatic conditions (e.g. rainfall variability) coupled with existing and future capacity of dam storage will determine the usage frequency and utilisation of augmented bulk desalination or recycled water supply sources over their life cycle. In some locations (i.e. mainly dry climates), desalination will be extensively utilised to contribute to base-load demand with only a few periods of standby mode or shutdown, while in others such as SEQ, the highly variable climatic conditions (i.e. cycles of dry and wet years) means that this factory water serves more as a water security insurance policy that is enacted less frequently but nonetheless ensures a reliable supply of potable water to a region. This latter type of plant has a considerably higher unit cost due to its infrequent mode of operation, but in most cases represents a lower cost than the alternative of having uncertain water supply future and the associated implications that this has on the viability of a populated urban region.

This increased ability also results in financial savings for water providers. As such, the long term reorganisation of the system through diversification of the water supply portfolio is of benefit to both consumers and water providers. 


\subsection{Water-energy-climate nexus: maximising climate mitigation}

Desalination plants may be a useful tool to deal with uncertainty, but like any insurance policy, this would see them sit idle for great lengths of time, only called into action intermittently. The energy intensity of current Australian desalination plants is up to 10 times greater than the energy presently consumed in supplying bulk water in SEQ (Hoang et al., 2009; White, 2009). This raises two significant arguments against their implementation.

The continuing advent of PRO technology could greatly nullify these problems and provide other supplementary benefits. For existing desalination plants, (Helfer et al., 2013) discusses replacing existing single purpose membranes with dual purpose alternatives, thereby transforming RO desalination plants into dual-purpose water supply and renewable energy production facilities. This could realistically occur at SEQ's Tugun plant when the existing membranes reach their lifespan limitations. This, as shown by the SDM model, would likely occur before SEQ requires additional desalination plants (in 30 years' time under the BAU D \& TDP scenario). Additional power generation capacity would also decrease the need for fossil fuel exploitation, or the development of other renewable power supply plants.

Clearly, there are myriad potential benefits of integrating this technology into the operation of the water resource system. The SDM indicates that under predicted future SEQ climatic conditions, desalination plants will be inactive for sufficient periods of time to allow generation of nearly half the energy consumed in manufacturing water. Thus, depending on capital costs, the investment in PRO technology in the future would be worthwhile in SEQ.

\subsection{Availability based pricing and revenue streams}

Rationing a scarce good equally among all consumers in a system is not economically efficient if those consumers are heterogeneous and have different marginal valuations for the good in question (Grafton and Ward, 2008). Despite these known economic inadequacies, most water governance bodies in Australia chose to implement water restrictions during the Millennium drought (2002-2009). A range of problematic outcomes have also resulted since the drought ceased. Across many of the populated state capitals of Australia water prices have continually increased well above the rate of inflation long after dams replenished , in an attempt to fund the increased marginal cost of water supply due to the debt load created during the drought (Killoran, 2013b). Ironically this is exacerbated by slow rebounds in water demand after sustained restrictions. If the escalating price trajectory is halted, forward planning and debt recovery are constrained, predisposing the system to further crisis in the future.

TDP, which is essentially an availability based pricing mechanism, acts to improve long-term price stability, increases self-funding, and negates the requirement for draconian restrictions. This treats water and water institutions with the same respect and flexibility observed in the rest of a market economy. Comparing 
the BAU scenario with the BAU D \& TDP scenario, the model indicates foregone revenue that has resulted from current water governance in the order of AUD\$4.9B by year 50, increasing to AUD\$18.9B in year 100. As demonstrated in the latter scenario, adopting TDP before the beginning of a water crisis, combined with using surplus revenues generated from the TDP to fund new rain-independent capital infrastructure, not only improve a regions water security, but reduces the post-drought interest burdens.

It should be noted that the water supply planning framework of the SEQ region has a state governmentowned monopoly bulk water entity (i.e. seqwater) that has a wholesale water price $(\$ / k L)$ that is passed to customers through three separate local government-owned water distribution/retail entities. These distribution entities have a separate distribution and retail price and structure (i.e. block tariffs, fixed verse variable cost ratio, etc.). While the TDP provides a good mechanism to generate revenues to fund expansion of bulk water supplies to ensure long-term water security, the equitable transfer of the TDP to individual customer segments is considered well outside the scope of this current paper. The current pricing approach would mean that the bulk water price and any availability-based TDP would be distributed to all customer segments equally and the water distribution entities have only their distribution/retail price components to target pricing at certain groups (i.e. high water users). Potentially, the bulk and distribution water entities could formulate bulk and retail pricing regimes that achieve the scarcity objectives of the region alongside social equity objectives (e.g. high consumers pay a relatively higher proportion of the TDP through a clever pricing scheme that integrates the bulk, distribution and retail prices into one stepped tariff structure for the customer).

\subsection{Navigating the response of the social system}

Adverse responses to TDP within the social system must be considered. The lower the level of available supplies relative to demand, and the higher the availability based price (i.e. TDP), the greater the community pressure on governments to subsidise water consumers and implicitly burden others is going to be. Whilst the socially responsible outcome is achieved with TDP, as increasingly costly uses of water get curtailed in homes and through industry sectors, the pressure will always be there for government to pass the costs to general taxpayers or other target groups. It should be noted that a TDP can incorporate equity considerations through coupling with block tariffs and consumer water budgets (i.e. all households are provided with a certain non-discretionary allocation of water at the base price).

Currently water governance bodies are faced with myriad uncertainties, without adequate tools to develop new policies, let alone convince the public of their merits. In order to make more optimal decisions, all known important factors and probabilities affecting the water supply system and its consumers must be taken into account. Therefore, decision makers should utilise a suitable method to solve this complex probabilistic, sequential and dynamic decision problem. The SDM model in this paper demonstrates the potential of a long-term, integrated approach to water governance to cope with oncoming population and 
climatic changes to the water resources system. This assumes that policy is maintained consistently across changes in government.

The timespans required for the implementation of TDP and desalination augmentation outlined in this paper exceed the length of local, state and federal government political cycles (4, 3 and 3 years respectively). If this policy, or any similarly significant change to water governance, is to withstand interference from the social system through politics, sound communication and accurate representation in the community must occur. It is unlikely that this could occur without bi-partisan consensus. The developed model and its outputs are well predisposed to assisting in this process, enabling stakeholders in the political arena and the community to understand alternative approaches to water governance.

\subsection{Future research}

All models are inevitably simplifications of the systems they mimic (Huggett, 1993). The SDM detailed in this paper was built to identify and understand the most important components of the water supply-demand system in the SEQ region, and explore how this system can be reorganised to cope with future challenges.

The next stages of the project will focus on: (1) converting the model to simulate other regions in Australia facing similar water dilemmas; (2) further investigating the technical side of PRO technology and its potential for integration in the SEQ water resources system; and (3) examining how long-term potable water demand patterns may change in residential homes and in industry.

\section{CONCLUSIONS}

This paper detailed the development of a SDM developed to explore the behaviour of the SEQ water resource system over the next 100 years under systemic change brought about by climate change and population growth. The current supply-side oriented approach to water governance was found to be illequipped to cope with these changes, leading to economic hardship and chronic water shortages.

Reorganisation of the system through new water governance practices were proposed and simulated. These included: (a) increasing supply with rain-independent sources; (b) managing demand by introducing availability based pricing; and (c) enhancing asset management decisions. The model demonstrated that by properly pricing water scarcity through TDP is a considerably more effective strategy for reducing demand while simultaneously generating the additional revenues necessary to fund essential bulk supply infrastructure. The study indicates that as the supply portfolio includes greater proportions of rainindependent supply sources such as desalination plants, the requirement for implementing the TDP regime diminishes since there is less reliability on inflow to dams and groundwater. 
Simulation of PRO technology integration into the rain-independent component of the supply network was found to have large potential to decrease climate related feedbacks caused by RO desalination, and greatly increase the utilisation of system infrastructure. The outcomes of the study have implications for government agencies and water supply utilities/businesses seeking to better manage their cities long-term water security interests.

\section{ACKNOWLEDGMENTS}

This research is part of a study on desalinated water in Australian bulk water supply networks, funded by a grant from the National Centre of Excellence in Desalination Australia (NCEDA) to the Alfred Deakin Research Institute (ADRI) at Deakin University, in a project jointly managed with the Smart Water Research Centre at Griffith University, and with technical cooperation from AECOM Ltd. The authors acknowledge valuable comments on this paper from Dr Helen Scarborough, David Downie, Dr Joel Byrnes and Dr Tom Quirk. The authors also gratefully acknowledge the funding from the Griffith Climate Change Response Program (GCCRP).

\section{REFERENCES}

ABS. 2012. Water account, Australia 2009-10 [Online]. [Canberra]: Australian Bureau of Statistics. Available: http://www.abs.gov.au/AUSSTATS/abs@.nsf/DetailsPage/4610.0200910?OpenDocument 2012].

Achilli, A. \& Childress, A. E. 2010. Pressure retarded osmosis: From the vision of Sidney Loeb to the first prototype installation - Review. Desalination, 261, 205-211.

Australian Government, CSIRO \& Australian National University. 2013. Climate adaptation outlook : a proposed national adaptation assessment framework [Online]. [Canberra, A.C.T.]: Department of Industry, Innovation, Climate Change, Science, Research and Tertiary Education. Available: http://www.climatechange.gov.au/climate-change/adapting-climate-change/climate-adaptationoutlook [Accessed July 2013.

Barker, A., Murray, T. \& Salerian, J. S. 2010. Developing a partial equilibrium model of an urban water system. Productivity Commission Staff Working Paper. Melbourne: Productivity Commission.

Bennett, N. D., Croke, B. F. W., Guariso, G., Guillaume, J. H. A., Hamilton, S. H., Jakeman, A. J., MarsiliLibelli, S., Newham, L. T. H., Norton, J. P., Perrin, C., Pierce, S. A., Robson, B., Seppelt, R., Voinov, A. A., Fath, B. D. \& Andreassian, V. 2013. Characterising performance of environmental models. Environmental Modelling \& Software, 40, 1-20.

BOM. 2013. Water storage [Online]. Commonwealth of Australia 2012, Bureau of Meteorology. Available: http://water.bom.gov.au/waterstorage/awris/ [Accessed January 2013.

Borshchev, A. \& Filippov, A. From System Dynamics and Discrete Event to Practical Agent Based Modelling: Reasons, Techniques, Tools. The 22nd International Conference of the System Dynamics Society, 2004 Oxford

Cavana, R. Y. \& Clifford, L. V. 2006. Demonstrating the utility of system dynamics for public policy analysis in New Zealand: the case of excise tax policy on tobacco. System Dynamics Review, 22, 321-348.

CSIRO 2012. Climate and water availability in south-eastern Australia a synthesis of findings from Phase 2 of the South Eastern Australian Climate Initiative (SEACI). In: Post, D. A., Timbal, B. \& Potter, N. J. (eds.) CSIRO Land and Water science report 1834-6618. [Canberra, A.C.T.?]: CSIRO.

Denver Water. 2013. Drought Pricing Schedule [Online]. Denver Water, . Available: http://www.denverwater.org/Drought/DroughtPricing/ [Accessed 25 May 2013 2013]. 
Fiddaman, T. S. 2002. Exploring policy options with a behavioral climate-economy model. System Dynamics Review, 18, 243-267.

Ford, A. 2005. Simulating the impacts of a strategic fuels reserve in California. Energy Policy, 33, 483-498.

Forrester, J. W. 1969. Urban dynamics, Cambridge, Mass.,, M.I.T. Press.

Forrester, J. W. 1971. World dynamics, Cambridge, Mass.,, Wright-Allen Press.

Forrester, J. W. 1996. System Dynamics and K-12 Teachers. Massachusetts Institute of Technology Cambridge, MA, USA.

Franck, T. R. 2009. Coastal Communities and Climate Change" A Dynamic Model of Risk Perception, Storms and Adaptation. PhD, Massachusetts Institute of Technology.

Frenkiel, F. N. \& Goodall, D. W. 1978. Simulation modelling of environmental problems, Chichester Eng. ; New York, Published on behalf of the Scientific Committee on Problems of the Environment of the International Council of Scientific Unions by Wiley.

Frontier Economics 2008. Approaches to urban water pricing. Waterlines occasional paper no 7. Canberra, A.C.T.: National Water Commission.

Frontier Economics 2011. Efficient water resource pricing in Australia: an assessment of administered scarcity pricing in urban areas. Waterlines report. Canberra ACT: National Water Commission.

Gharib, S. 2008. Synthesizing System Dynamics and Geographic Information Systems in a new method to Model and Simulate Environmental Systems. PhD, University of Bergen.

Grafton, R. Q. \& Ward, M. B. 2008. Prices versus rationing: Marshallian surplus and mandatory water restrictions. Economic Record, 84, S57-S65.

Grafton, R. Q. \& Ward, M. B. 2010. Dynamically Efficient Urban Water Policy. Revision 2 ed.: Centre for Water Economics, Environment and Policy, The Australian National University.

Hassanzadeh, E., Elshorbagy, A., Wheater, H. \& Gober, P. 2014. Managing water in complex systems: An integrated water resources model for Saskatchewan, Canada. Environmental Modelling \& Software, $58,12-26$.

Heggen, R. J. 2000. Rainwater catchment and the challenges of sustainable development. Water, Science and Technology, 42, 141-145.

Helfer, F., Sahin, O., Lemckert, C. \& Annisimov, Y. G. Salinity Gradient Energy: a New Source of Renewable Energy for Australia. 8th International Conference of the European Water Resources Association, 2013 Porto, Portugal.

Hennessy, K., Fitzharris, B., Bates, B., Harvey, N., Howden, S., Hughes, L., Salinger, J. \& Warrick, R. 2007. Australia and New Zealand. Climate Change 2007: Impacts, Adaptation and Vulnerability. Contribution of Working Group II to the Fourth Assessment Report of the Intergovernmental Panel on Climate Change.

Hoang, M., Bolto, B., Haskard, C., Barron, O., Gray, S. \& Leslie, G. 2009. Desalination in Australia. Water for a Healthy Country Flagship Report series ISSN: 1835-095X. Clayton, Victoria: CSIRO.

Hoffmann, M., Worthington, A. \& Higgs, H. 2006. Urban water demand with fixed volumetric charging in a large municipality: the case of Brisbane, Australia. Australian Journal of Agricultural and Resource Economics, 50, 347-359.

Homer, J., Hirsch, G. \& Milstein, B. 2007. Chronic illness in a complex health economy: the perils and promises of downstream and upstream reforms. System Dynamics Review, 23, 313-343.

Huggett, R. J. 1993. Modelling the human impact on nature : systems analysis of environmental problems, Oxford ; New York, Oxford University Press.

Hughes, N. 2008. Urban water management : optimal price and investment policy under climate variability, Canberra, A.C.T., ABARE - Australian Bureau of Agricultural and Resource Economics.

Hughes, N., Hafi, A. \& Goesch, T. 2009. Urban water management: optimal price and investment policy under climate variability. Australian Journal of Agricultural and Resource Economics, 53, 175-192. 
Jenkins, M. W., Lund, J. R. \& Howitt, R. E. 2003. Economic losses for urban water scarcity in California. Journal of the American Water Works Association, 95.

Jenkins, M. W., Lund, J. R. \& Howitt, R. E. 2013. Economic Losses for Urban Water Scarcity in California. Davis: University of California.

Kauffman, S. 1993. The Origins of Order: Self-Organization and Selection in Evolution, Oxford University Press, USA.

Kelly, R. A., Jakeman, A. J., Barreteau, O., Borsuk, M. E., ElSawah, S., Hamilton, S. H., Henriksen, H. J., Kuikka, S., Maier, H. R., Rizzoli, A. E., Delden, H. \& Voinov, A. A. 2013. Selecting among five common modelling approaches for integrated environmental assessment and management. Environmental Modelling \& Software, 47, 159-181.

Killoran, M. 2013a. Desal plant haemorrhaging money [Online]. Gold Coast: Digital News Media. Available: $\quad$ http://prelive.goldcoast.com.au/article/2013/06/06/452794_gold-coast-news.html [Accessed 28 June 2013.

Killoran, M. 2013b. Gold Coast water torture continues as prices set to soar. Gold Coast Bulletin [Online]. Available: $\quad$ http://www.goldcoastbulletin.com.au/news/gold-coast/gold-coast-water-torturecontinues-as-prices-set-to-soar/story-fnj94idh-1226774485471 [Accessed 10 December].

Kirkwood, C. W. 1998. System Dynamics Methods: A Quick Introduction [Online]. Available: http://www.public.asu.edu/ kirkwood/sysdyn/SDIntro/SDIntro.htm [Accessed 10 September 2006.

Langsdale, S., Beall, A., Carmichael, J., Cohen, S., Forster, C. \& Neale, T. 2009. Exploring the Implications of Climate Change on Water Resources through Participatory Modeling: Case Study of the Okanagan Basin, British Columbia. Journal of Water Resources Planning and Management, 135(5), 373-381.

Loeb, S. 2001. One hundred and thirty benign and renewable megawatts from Great Salt Lake? The possibilities of hydroelectric power by pressure-retarded osmosis. Desalination, 141, 85-91.

Loucks, D. P. \& van Beek, E. 2005. Water resources systems planning and management : an introduction to methods, models and applications, Paris, Unesco.

Mannermaa, M. 1991. In search of an evolutionary paradigm for futures research. Futures, 23, 349-372.

Marsden, J. \& Pickering, P. 2006. Securing Australia's urban water supplies opportunities and impediments. Camberwell, Vic. Australia: Marsden Jacob Associates.

Meadows, D. H., Meadows, D. L., Randers, J. \& Behrens, W. 1972. The Limits to Growth, New York, NY, Universe Books.

Moss, R. H., Edmonds, J. A., Hibbard, K. A., Manning, M. R., Rose, S. K., van Vuuren, D. P., Carter, T. R., Emori, S., Kainuma, M., Kram, T., Meehl, G. A., Mitchell, J. F. B., Nakicenovic, N., Riahi, K., Smith, S. J., Stouffer, R. J., Thomson, A. M., Weyant, J. P. \& Wilbanks, T. J. 2010. The next generation of scenarios for climate change research and assessment. Nature, 463, 747-756.

NCEDA 2010. Australian desalination research roadmap, Rockingham, Western Australia, National Centre of Excellence in Desalination, Murdoch University.

NWC. 2006. Australia's water supply status and seasonal outlook Available: http://archive.nwc.gov.au/_data/assets/pdf file/0019/8830/Australia-water-supply-seasonaloutlook-PUB-.pdf [Accessed December 2012].

Olmstead, S. M., Hanemann, W. M. \& Stavins, R. N. 2007. Water demand under alternative price structures. Journal of Environmental Economics and Management, 54, 181-198.

Oreskes, N. 2004. Beyond the ivory tower - The scientific consensus on climate change. Science, 306, 16861686.

Ossimitz, G. \& Mrotzek, M. The Basics of System Dynamics: Discrete vs. Continuous Modelling of Time. The 2008 International Conference of the System Dynamics Society, 2008 Athens, Greece.

Patten, B. C. \& Jørgensen, S. E. 1995. Complex Ecology: The Part-Whole Relation in Ecosystems, Englewood Cliffs, New Jersey, Prentice Hall. 
Pearce, K., Holper, P., Hopkins, M., Bouma, W., Whetton, P., Hennessy, K. \& Power, S. 2007. Climate change in Australia Technical Report 2007, Canberra, Australia.

Pink, B. 2012. 2012 Year Book Australia, Canberra, Australia, The Australian Bureau of Statistics.

Pittock, J. \& Connell, D. 2010. Australia Demonstrates the Planet's Future: Water and Climate in the Murray-Darling Basin. International Journal of Water Resources Development, 26, 561-578.

Polhill, J. G. \& Gotts, N. M. 2009. Ontologies for transparent integrated human-natural system modelling. Landscape Ecology, 24, 1255-1267.

Queensland Treasury 2011. Population projections to 2031: local government areas. In: The Queensland Treasury - Office of Economic and Statistical Research Demography and Planning (ed.) 2011 ed.

QWC 2010. South East Queensland water strategy, City East, Qld., Queensland Water Commission.

QWC. 2012a. South East Queensland System Operating Plan Revision 5 [Online]. Queensland Water Commission. Available: http://www.dews.qld.gov.au/ data/assets/pdf file/0014/31406/seqsystem-operating-plan5.pdf [Accessed May 2013.

QWC 2012b. South East Queensland Water Strategy - Annual Report 2012, City East, Qld., Queensland Water Commission.

Robinson, J. 2003. Future subjunctive: backcasting as social learning. Futures, 35, 839-856.

Sahin, O. \& Mohamed, S. 2009. Decision Dilemmas for Adaptation to Sea Level Rise: How to, when to? In: Sun, H., Jiao, R. \& Xie, M. (eds.) IEEE 2009 International Conference on Industrial Engineering and Engineering Management. Hong Kong: IEEE.

Sahin, O. \& Mohamed, S. 2013. A spatial temporal decision framework for adaptation to sea level rise. Environmental Modelling \& Software, 46, 129-141.

Scholl, H. J. J. Agent-Based and System Dynamics Modeling : A Call for Cross Study and Joint Research. Procedings of the 34th Annual Hawaii International Conference on System Sciences, 2001a.

Scholl, H. J. J. Looking Across the Fence: Comparing Findings From SD Modeling Efforts With those of Other Modeling Techniques. Proceedings of the 19th Int. Conference of the SD Society, $2001 \mathrm{~b}$.

SEQ Water Grid 2011. SEQ Water Grid Annual Operations Plan. SEQ Water Grid.

Siems, R., Sahin, O., Talebpour, M., Stewart, R. \& Hopewell, M. Energy intensity of decentralised water supply systems utilised in addressing water shortages. 8th International Conference of the European Water Resources Association, 2013 Porto, Portugal.

Sivertsen, E., Holt, T., Thelin, W. \& Brekke, G. 2012. Modelling mass transport in hollow fibre membranes used for pressure retarded osmosis. Journal of Membrane Science, 417-418, 69-79.

SoE. 2013. Australia state of the environment 2011. Independent report to the Australian Government Minister for Sustainability, Environment, Water, Population and Communities [Online]. Canberra, Australia: Department of Sustainability, Environment, Water, Population and Communities. Available: http://www.environment.gov.au/soe/2011/report/inland-water/3-1-recent-climate.html [Accessed January 2013.

Sojda, R. S. 2007. Empirical evaluation of decision support systems: Needs, definitions, potential methods, and an example pertaining to waterfowl management. Environmental Modelling \& Software, 22, 269-277.

Sterman, J. D. 2008. Economics - Risk communication on climate: Mental models and mass balance. Science, 322, 532-533.

Stewart, R. 2011. Verifying the end use potable water savings from contemporary residential water supply schemes. Waterlines report. Canberra, Australia: National Water Commission.

Thorsen, T. \& Holt, T. 2009. The potential for power production from salinity gradients by pressure retarded osmosis. Journal of Membrane Science, 335, 103-110.

Van den Belt, M., Dietz, T., van den Belt, M. \& ebrary Inc. 2004. Mediated modeling : a system dynamics approach to environmental consensus building, Washington, DC, Island press. 
Vennix, J. A. M., Akkermans, H. A. \& Rouwette, E. A. J. A. 1996. Group model-building to facilitate organizational change: An exploratory study. System Dynamics Review, 12, 39-58.

Ventana Systems 2012. Vensim DSS. 6.0b ed. Harvard, MA: Ventana Systems, Inc.

Voinov, A. 2008. Systems science and modeling for ecological economics, Amsterdam ; London, Elsevier Academic Press.

White, I. W. 2009. Decentralised Environmental Technology Adoption: The household experience with rainwater harvesting. PHD Griffith University.

World Economic Forum Water Initiative 2011. National Security. Water Security : The Water-Food-EnergyClimate Nexus. Island Press/Center for Resource Economics.

Zhang, B. 2008. A Study of GIS-SD Based Temporal-Spatial Modelling Of Water Quality In Water Pollution Accidents. ISPRS Congress Beijing 2008, Proceedings of Commission II. Beijing Reed Business Geo. 